\title{
Calculation of Lead-Iron Double-Layer Thickness for Gamma-Ray Shielding by MATLAB Program
}

\author{
Sarai Lekchaum and Kitsakorn Locharoenrat \\ King Mongkut's Institute of Technology Ladkrabang, Bangkok, Thailand \\ Correspondence should be addressed to Kitsakorn Locharoenrat; kitsakorn.lo@kmitl.ac.th
}

Received 27 July 2017; Accepted 13 November 2017; Published 28 November 2017

Academic Editor: Arkady Serikov

Copyright ( 2017 Sarai Lekchaum and Kitsakorn Locharoenrat. This is an open access article distributed under the Creative Commons Attribution License, which permits unrestricted use, distribution, and reproduction in any medium, provided the original work is properly cited.

\begin{abstract}
This contribution is aimed at designing the optimal thickness of lead-iron double-layer container to store a radioactive waste releasing the photon energy at $1.3325 \mathrm{MeV}$ and initial radiation intensity at $100 \mathrm{mSv} / \mathrm{hr}$ using the optimization design by MATLAB software. This design consisted of three parts of calculations to achieve 1000 times the radiation attenuation of container. The first was the logarithmic interpolation for the mass attenuation coefficient. The second was the bilogarithmic interpolation for the exposure buildup factor. The third was the contour-plotting analytical technique for the optimal thickness of radiation container. The values of mass attenuation coefficient and exposure buildup factor were exactly validated as compared with the standard reference database. Furthermore, we have found that the optimal thickness was $3.2 \mathrm{~cm}$ for lead (1st layer) and $17.0 \mathrm{~cm}$ for iron $(2 \mathrm{nd}$ layer). Container weight was $994.30 \mathrm{~kg}$, whilst container cost was $167.30 \mathrm{USD}$. The benefit of our design can quickly and precisely apply for the radiation safety assessment of the occupational radiation workers who always work in the nuclear reactor area.
\end{abstract}

\section{Introduction}

Although nuclear technology is very useful for researches and industries, maintenance of nuclear reactor is necessary for the safety reason. International Commission on Radiological Protection (ICRP) has suggested that the limitation of radiation exposure dose for occupational radiation worker is $20 \mathrm{mSv} /$ year [1]. During the maintenance period, Thailand Institute of Nuclear Technology (TINT) has informed that the gamma radiation intensity of a bolt taken from the nuclear reactor was about $100 \mathrm{mSv} / \mathrm{hr}$, whereas photon energy was $1.3325 \mathrm{MeV}$ that was similar to Co-60 source. Consequently, this is considered as a radioactive waste. To evaluate the radiation safety due to the nuclear interactions, one of the best ways is the use of Monte Carlo simulation [2-4]. According to Monte Carlo approach, statistical processing time is prolonged at $13 \mathrm{hrs}$ partly due to the complex geometry design $[5,6]$. To avoid wasting of time, MATLAB software is certainly introduced to calculate the thickness of materials. This thickness will be used as an input variable in Monte Carlo simulation to reduce wasting of time. There are four advantages for MATLAB. First, this software is able to plot the contour graph to analyze the optimal thickness of materials. This contour-plotting technique is easy and more suitable than 3D surface plotting technique for finding the optimum solution [7]. Second, there are a variety of commands used in for-loop and if-clause processes [8] which are important components for the optimization model. Third, output data stored in matrix format after mathematical processing is very simple for the next mathematical process. Last, the command patterns in calculation for processing data are easily written.

Here we have performed the calculations for shielding materials of lead and iron layers for a $1.3325 \mathrm{MeV}$ and $100 \mathrm{mSv} / \mathrm{hr}$ gamma-ray by MATLAB software. This design is comprised of three parts. The first and second parts are the logarithmic interpolation for mass attenuation coefficient and the bilogarithmic interpolation for exposure buildup factor, respectively. These parts are compared with the standard reference database from National Institute of Standards and Technology (NIST) [9] and American National Standard (ANS-6.4.3) for checking a validation [10]. The third part is to apply this optimization model to determine the suitable 


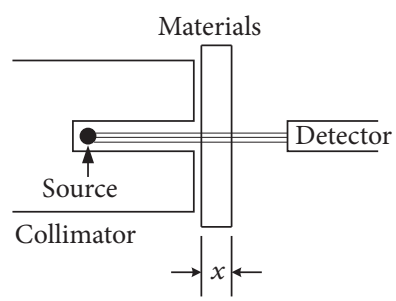

(a)

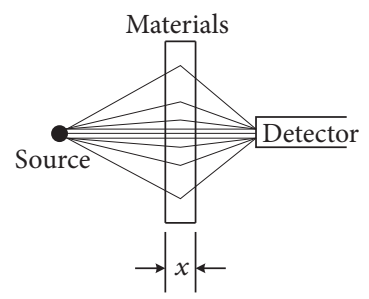

(b)

FIGURE 1: Geometry for gamma-ray attenuation for (a) a narrow beam geometry and (b) a board beam geometry. $x$ was the thickness of designed materials.

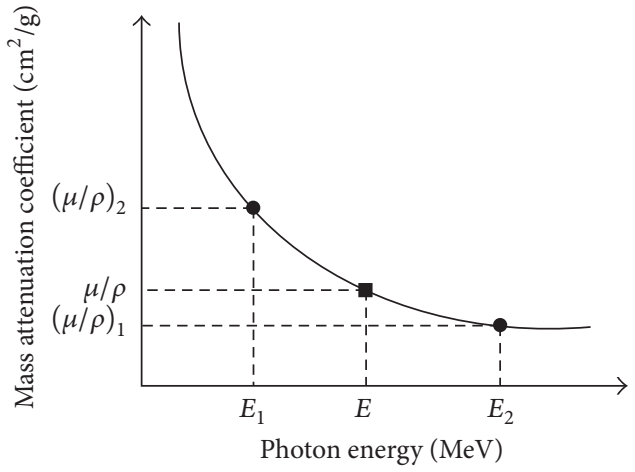

(a)

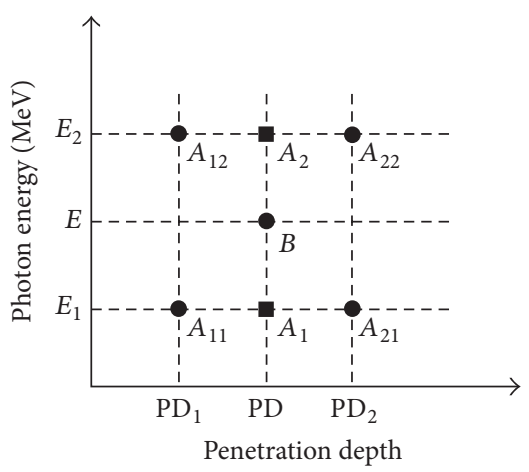

(b)

FIGURE 2: Method of interpolations: (a) logarithmic interpolation and (b) bilogarithmic interpolation.

double-layer thickness (lead-iron) for attenuating radiation intensity of $0.1 \mathrm{mSv} / \mathrm{hr}$ via the contour-plotting analytical technique.

\section{Simulation Procedures}

2.1. Mathematical Format for Optimization. Objective function was defined as the gamma attenuation of doublelayer materials in a narrow (Figure 1(a)) and board beam (Figure 1(b)) [11].

To achieve 1000 times the radiation attenuation of container as informed by TINT and to follow the radiation dose limitation as informed by ICRP, our objective function was limited at $0.1 \mathrm{mSv} / \mathrm{hr}$ or

$$
\begin{aligned}
f\left(x_{1}, x_{2}\right) & =I=I_{0} B_{1} B_{2} e^{-\mu_{1} x_{1}-\mu_{2} x_{2}} \\
& \leq 0.1 \begin{cases}B_{1} B_{2}=1, & \text { for a narrow beam, } \\
B_{1} B_{2}>1, & \text { for a board beam, }\end{cases}
\end{aligned}
$$

where $I_{0}$ and $I$ were the initial and transmitted radiation intensity $(\mathrm{mSv} / \mathrm{hr})$, respectively. $\mu_{1}$ and $\mu_{2}$ were the linear attenuation coefficient $\left(\mathrm{cm}^{-1}\right)$ of lead and iron, respectively. $B_{1}$ and $B_{2}$ were the exposure buildup factor of lead and iron, respectively. Mass attenuation coefficient $(\mu / \rho)$ was calculated by (2) according to logarithmic interpolation (LI) as shown in Figure 2(a) $[12,13]$. Exposure buildup factor (B) was computed by (3)-(5) according to bilogarithmic interpolation (BI) modified from bilinear interpolation as seen in Figure 2(b) $[14,15]$.

$$
\begin{aligned}
\frac{\mu}{\rho} & \\
= & \frac{(\mu / \rho)_{1}\left(\log E_{2}-\log E\right)+(\mu / \rho)_{2}\left(\log E-\log E_{1}\right)}{\log E_{2}-\log E_{1}}, \\
B & =\frac{\left(A_{1}\right)\left(\log E_{2}-\log E\right)+\left(A_{2}\right)\left(\log E-\log E_{1}\right)}{\log E_{2}-\log E_{1}},
\end{aligned}
$$

where

$$
\begin{aligned}
& A_{1} \\
& =\frac{\left(A_{11}\right)\left(\log \mathrm{PD}_{2}-\log \mathrm{PD}\right)+\left(A_{21}\right)\left(\log \mathrm{PD}-\log \mathrm{PD}_{1}\right)}{\log \mathrm{PD}_{2}-\log \mathrm{PD}_{1}} \\
& A_{2} \\
& =\frac{\left(A_{12}\right)\left(\log \mathrm{PD}_{2}-\log \mathrm{PD}\right)+\left(A_{22}\right)\left(\log \mathrm{PD}-\log \mathrm{PD}_{1}\right)}{\log \mathrm{PD}_{2}-\log \mathrm{PD}_{1}} \\
& \mathrm{PD}_{1}=\mu_{1} \cdot x_{1} \\
& \mathrm{PD}_{2}=\mu_{2} \cdot x_{2}
\end{aligned}
$$




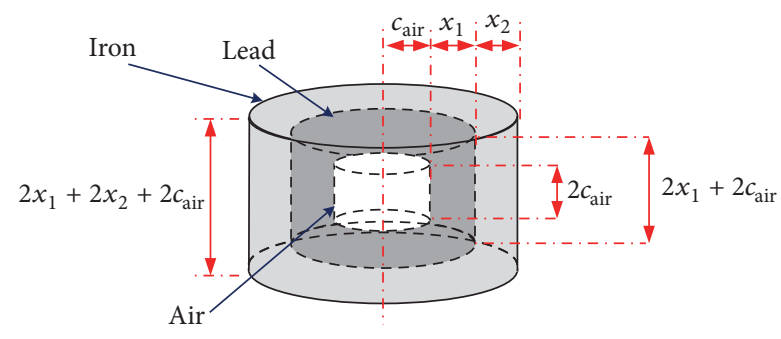

FIGURE 3: 3D configuration of container.

Constrained functions were divided into three parts: material thickness, weight, and cost. 3D and 2D configuration of containers were illustrated in Figures 3 and 4, respectively.

For economical reason, constrained function of the double-layer thickness of cylindrical container was limited at $30 \mathrm{~cm}$ or

$$
g_{1}\left(x_{1}, x_{2}\right): c_{\text {air }}+x_{1}+x_{2} \leq 30 \text {. }
$$

For technical reason, constrained function of the container weight was limited at $1,000 \mathrm{~kg}$ or

$$
\begin{gathered}
g_{2}\left(x_{1}, x_{2}\right): \frac{2 \pi}{1000}\left\{\rho_{a} c_{\text {air }}^{3}+\rho_{l}\left[\left(x_{1}+c_{\text {air }}^{3}\right)^{3}-c_{\text {air }}^{3}\right]\right. \\
\left.+\rho_{i}\left[\left(x_{1}+x_{2}+c_{\text {air }}\right)^{3}-\left(x_{1}+c_{\text {air }}\right)^{3}\right]\right\} \leq 1000
\end{gathered}
$$

where $\rho_{a}, \rho_{l}, \rho_{i}$ were the density of air, lead, and iron $\left(\mathrm{g} / \mathrm{cm}^{3}\right)$, respectively. $c_{\text {air }}$ was the radius of the gap inside a container.

For economical reason, constrained function of the container's cost was limited at 800 USD or

$$
\begin{aligned}
& g_{3}\left(x_{1}, x_{2}\right): \frac{4.4 \pi}{1000}\left\{A \rho_{l}\left[\left(x_{1}+c_{\text {air }}\right)^{3}-c_{\text {air }}^{3}\right]\right. \\
& \left.+B^{\prime} \rho_{i}\left[\left(x_{1}+x_{2}+c\right)^{3}-\left(x_{1}+c_{\text {air }}\right)^{3}\right]\right\} \leq 800,
\end{aligned}
$$

where $A, B^{\prime}$ were the cost of lead at $0.97 \mathrm{USD} / \mathrm{lb}$ as of April 21,2017 [16] and iron at $0.028 \mathrm{USD} / \mathrm{lb}$ as of January 31, 2017 [17], respectively.

2.2. Contour Plot Technique. Photon energy $(E=1.3325 \mathrm{MeV})$, initial radiation intensity $\left(I_{0}=100 \mathrm{mSv} / \mathrm{hr}\right)$, material \#1 (Pb), material $\# 2(\mathrm{Fe})$, material $\# 1$ thickness $(21.0 \mathrm{~cm})$, and material $\# 2$ thickness $(2.0 \mathrm{~cm})$ were imported as the input variables into MATLAB. Hence, linear attenuation coefficient, penetration depth, and exposure buildup factor were calculated as shown in Figure 5 in order to obtain the contour plot.

In detail, the mass attenuation coefficient $(\mu / \rho)$ from (2) was calculated as shown in Figure 6. After getting the penetration depth (PD) from (6), the exposure buildup factor (B) from (3)-(5) was preceded as shown in Figure 7.

\section{Results and Discussion}

3.1. Mass Attenuation Coefficient and Exposure Buildup Factor. To investigate a validation of MATLAB, we firstly check $\mu / \rho$ according to condition 1 (red frame from Figure 6). For instance, when $E_{\text {input }}$ is $0.15 \mathrm{MeV}$, we get $\mu / \rho=0.143600 \mathrm{~cm}^{2} / \mathrm{g}$ from MATLAB that is the same number as informed by NIST [9]. On the other hand, we check $B$ according to condition 1 (red frame from Figure 7). For example, when we have $\mathrm{PD}_{\text {input }}$ $=5 \mathrm{mfp}$ and $E_{\text {input }}=20 \mathrm{MeV}$, we get $B=5.22$ from MATLAB that is the same number as ANS-6.4.3 [10]. This number also gives better results than invariant embedding method (IEM) [18].

In our study, if we have $E_{\text {input }}=1.3325 \mathrm{MeV}$ according to C-60 and $I_{0}=100 \mathrm{mSv} / \mathrm{hr}$, the mass attenuation coefficient and exposure buildup factor are calculated in Table 1 and they are summarized in Figure 8.

3.2. Optimal Double-Layer Thickness. To understand the effects of container thickness on the container weight and cost, the space or void inside the container $\left(c_{\text {air }}\right)$ calculated by (7) is varied from 0 to $30 \mathrm{~cm}$. The results are shown in Figure 9. It is observed that container's weight and cost calculated by (8)-(9) tend to increase if we increase the gap inside the container.

However, when we assume $c_{\text {air }}=7.0 \mathrm{~cm}$ that is possibly suitable for keeping the radioactive waste, the optimal thickness analysis on the contour graph is presented in Figure 10. This optimal solution is identified as an intersection between the objective function $f(x)$ and the all constrained functions $g(x)$ [7]. Coordinate points on this identified line (red arrow in Figure 10) are therefore taken to calculate the weight and cost of container as shown in Table 2.

Finally, the optimal double-layer thickness selected from the identified line is $x_{1}=3.2 \mathrm{~cm}$ (lead) and $x_{2}=17.0 \mathrm{~cm}$ (iron). Thus, container's weight and cost are $994.30 \mathrm{~kg}$ and 167.30 USD, respectively.

To sum up, this optimization model concerns two merits. One is that the users are able to modify whatever the parameters (i.e., photon energy, initial intensity, material types and thicknesses, and material weight and cost) are to obtain the optimal thickness of materials of interests. Another one is that the simulation time is very fast just $10 \mathrm{sec}$.

\section{Conclusions}

From optimization model of the double-layer shielding design and selection of lead and iron cylindrical container by MATLAB software to store the radioactive waste at $1.3325 \mathrm{MeV}$ and $100 \mathrm{mSv} / \mathrm{hr}$, we have found that the mass attenuation coefficient and exposure buildup factor were $0.056601 \mathrm{~cm}^{2} / \mathrm{g}$ for lead, $0.051862 \mathrm{~cm}^{2} / \mathrm{g}$ for iron and 4.7316 for lead, 1.6681 for iron, respectively. These numbers were the same as the standard reference database. The doublelayer thickness selected from the analysis on contour-plotting graph was $3.2 \mathrm{~cm}$ for lead and $17.0 \mathrm{~cm}$ for iron to achieve 1000 times the radiation attenuation of container $(0.1 \mathrm{mSv} / \mathrm{hr})$. The total container weight and cost from these designed materials were $994.30 \mathrm{~kg}$ and $167.30 \mathrm{USD}$, respectively. 




(a)

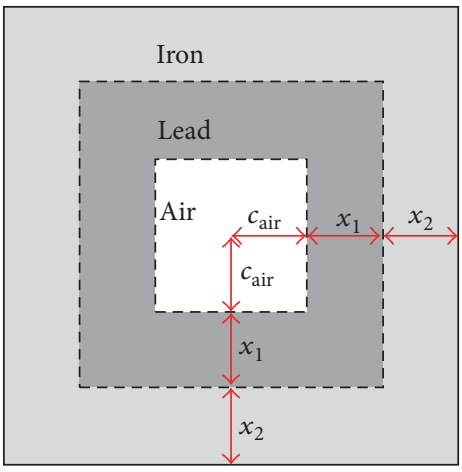

(b)

FIGURE 4: 2D configuration of container: (a) top view and (b) side view.

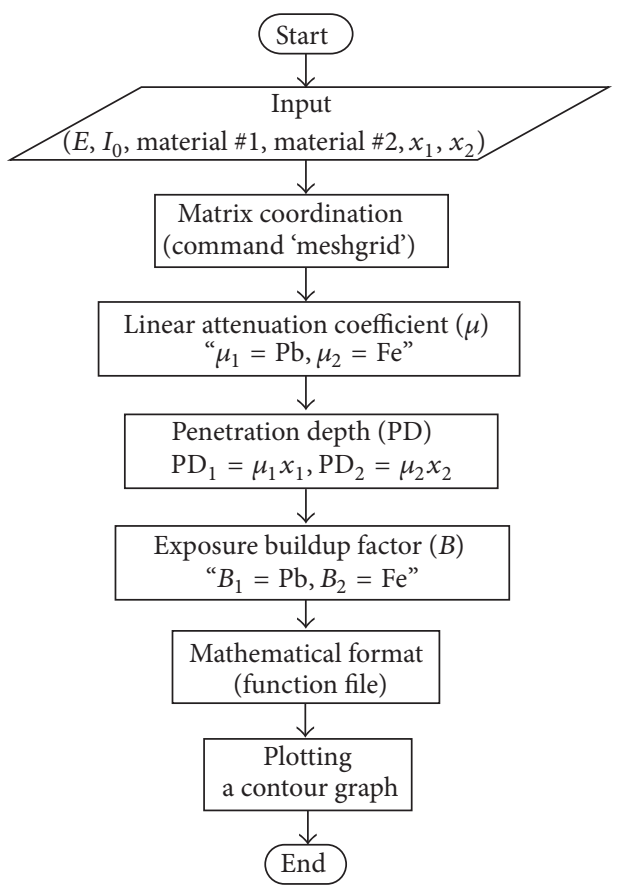

FIGURE 5: Overview flowchart of plotting a contour graph.

TABLE 1: Calculated mass attenuation coefficient $(\mu / \rho)$ and exposure buildup factor $(B)$ at $E_{\text {input }}=1.3325 \mathrm{MeV}$. PD is calculated from (6).

\begin{tabular}{lccccc}
\hline Layer & $\rho$ & $\mu / \rho$ & $\mu$ & $x$ & PD \\
\hline 1 = lead & $11.35 \mathrm{gm} / \mathrm{cm}^{3}$ & $0.0566 \mathrm{~cm}^{2} / \mathrm{g}$ & $0.6424 \mathrm{~cm}^{-1}$ & $21.0 \mathrm{~cm}$ & 13.4904 \\
$2=$ iron & $7.874 \mathrm{gm} / \mathrm{cm}^{3}$ & $0.0518 \mathrm{~cm}^{2} / \mathrm{g}$ & $0.4083 \mathrm{~cm}^{-1}$ & $2.0 \mathrm{~cm}$ & 4.7316 \\
\hline
\end{tabular}

TABLE 2: Container's weight and cost from the optimal solution by MATLAB.

\begin{tabular}{lcccc}
\hline$c_{\text {air }}(\mathrm{cm})$ & $x_{1}(\mathrm{~cm})$ & $x_{2}(\mathrm{~cm})$ & Weight $(\mathrm{kg})$ & Cost (USD) \\
\hline 7 & 7.0 & 11.0 & 808.40 & 838.80 \\
704.60 \\
7 & 6.4 & 12.0 & 860.00 & 356.50 \\
7 & 5.7 & 13.0 & 893.80 & 305.00 \\
7 & 5.1 & 14.0 & 929.40 & 266.10 \\
7 & 4.5 & 15.0 & 943.90 & 231.30 \\
7 & 3.7 & 16.0 & 994.30 & 188.50 \\
7 & 3.2 & 17.0 & 167.30 \\
\hline
\end{tabular}




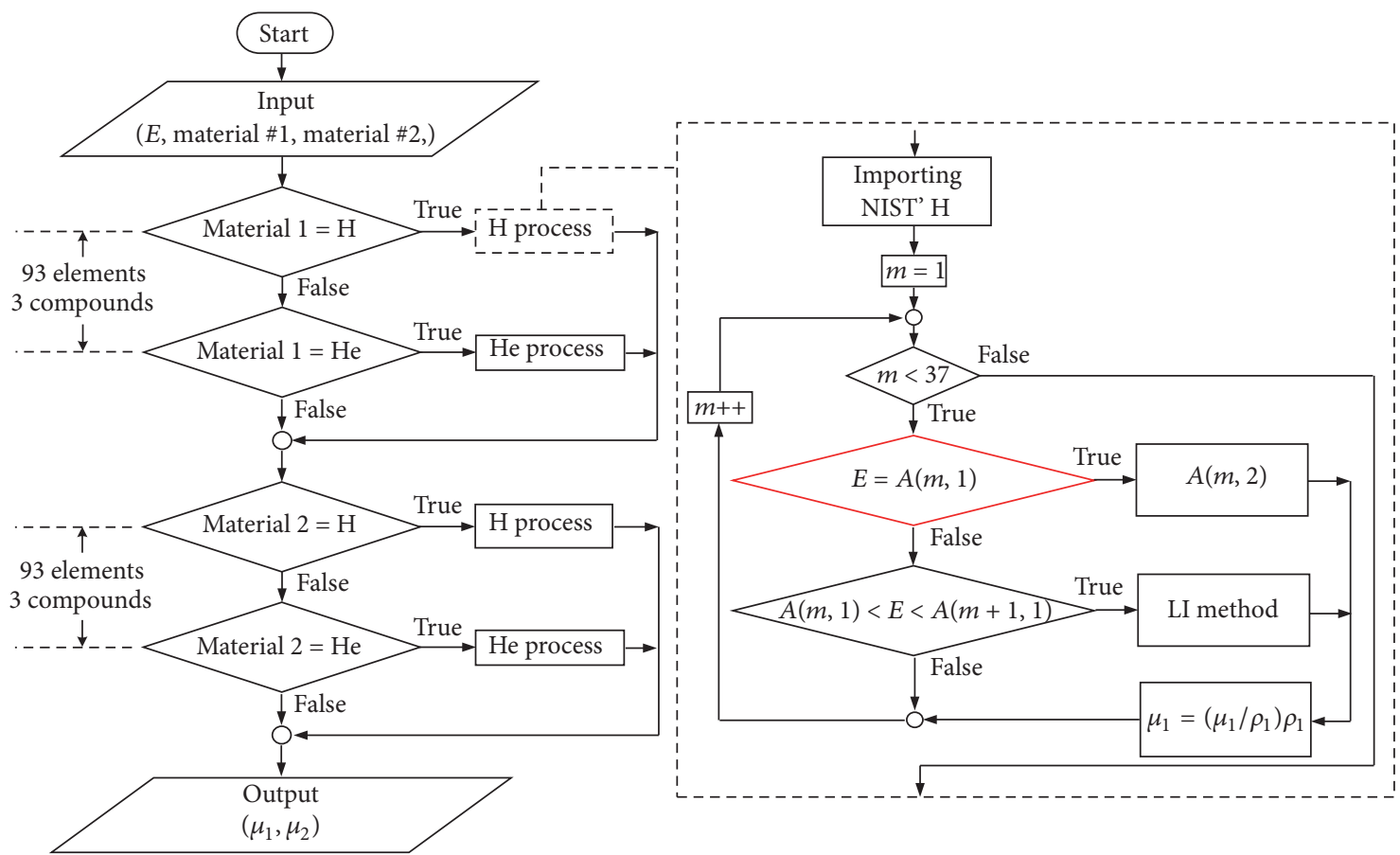

FIGURE 6: Flowchart of mass attenuation coefficient $(\mu / \rho)$ calculation.


Figure 7: Flowchart of exposure buildup factor $(B)$ calculation. 


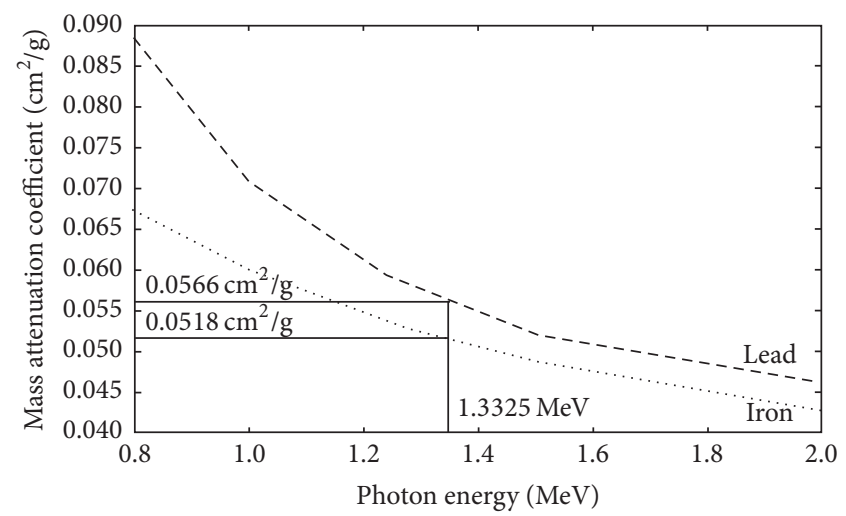

(a)

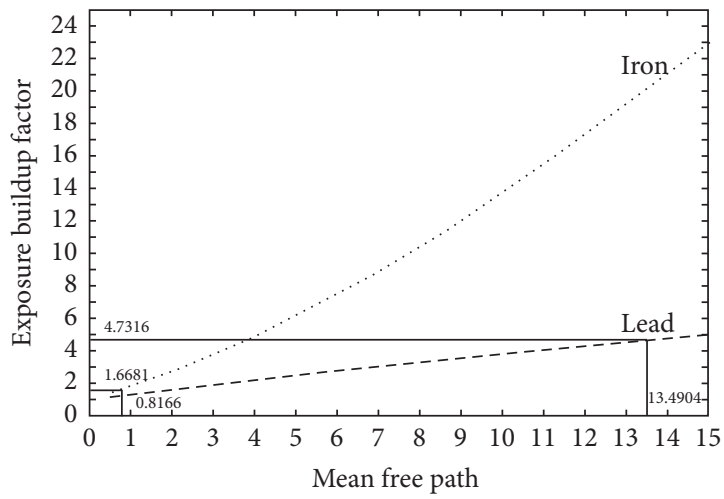

(b)

FIGURE 8: Summary of MATLAB calculation for (a) mass attenuation coefficient $(\mu / \rho)$ and (b) exposure buildup factor $(B)$.

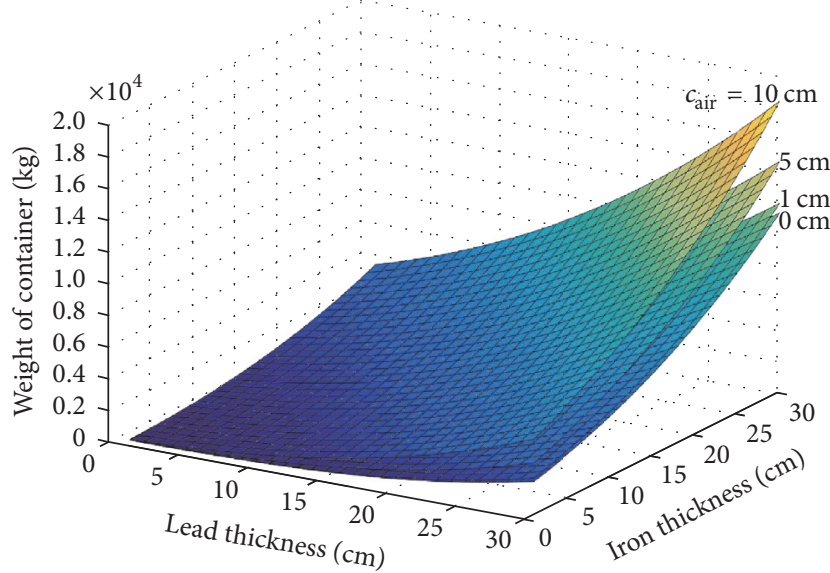

(a)



(b)

FIGURE 9: Variation of the space or void $\left(c_{\text {air }}\right)$ of container on (a) container weight and (b) container cost.

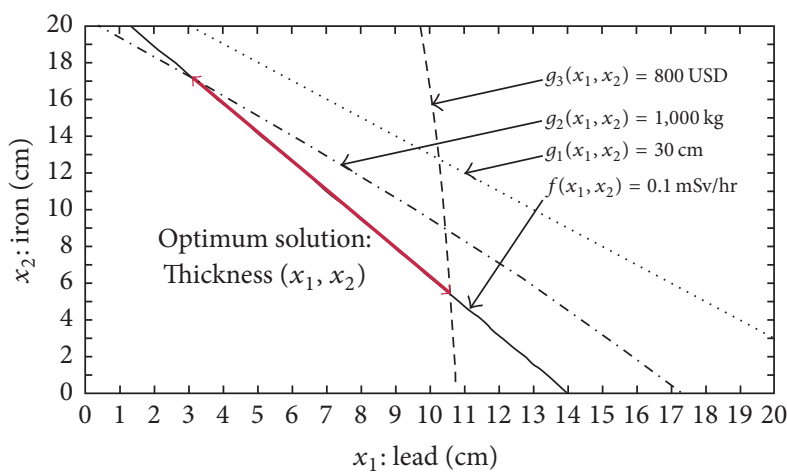

FIGURE 10: Contour-plotting graph for determination of the optimal double-layer thickness.

\section{Conflicts of Interest}

The authors declare no conflicts of interest.

\section{Acknowledgments}

This work was supported by King Mongkut's Institute of Technology Ladkrabang, Bangkok 10520, Thailand. The authors also thank Kittiphot Songkaitiwong for helpful discussions.

\section{References}

[1] HPS Specialists in Radiation Protection, 2017. https://hps.org/ publicinformation/ate/q8900.html.

[2] N. V. Hai and N. V. Hung, "Using weight window in MCNPX to calculate and simulate dose distribution at outside of treatment room in Dong Nai General Hospital to radiation safety assessment for this area," International Journal of Science and Research, vol. 3, no. 12, pp. 445-448, 2014.

[3] V. P. Singh, A. M. Ali, N. M. Badiger, and A. M. El-Khayatt, "Monte Carlo simulation of gamma ray shielding parameters of concretes," Nuclear Engineering and Design, vol. 265, pp. 10711077, 2013. 
[4] R. Merk, H. Kröger, L. Edelhäuser-Hornung, and B. Hoffmann, "PENELOPE-2008 Monte Carlo simulation of gamma exposure induced by $60 \mathrm{Co}$ and NORM-radionuclides in closed geometries," Applied Radiation and Isotopes, vol. 82, pp. 20-27, 2013.

[5] Los Alamos Laboratory, MCNP - A General Monte Carlo NParticle Transport Code (Version 5) Volume 1: Overview and Theory, USA, 2003.

[6] Los Alamos Laboratory, MCNP - A General Monte Carlo NParticle Transport Code (Version 5) Volume 2: User's Guide, USA, 2003.

[7] O. Venkataraman, Applied Optimization with MATLAB Programming, Wiley, USA, 2009.

[8] S. J. Chapman, MATLAB Programming with Applications for Engineers, Cengage Learning, USA, 2012.

[9] Physical Measurement Laboratory, National Institute of Standards and Technology, X-ray Mass Attenuation Coefficients, USA, 1996.

[10] Oak Ridge National Laboratory, American National Standard, New Gamma-Ray Buildup Factor Data, USA, 1988.

[11] M. Al-Arif and D. Kakil, "Calculated-Experimental Model for Multilayer Shield," Aro, The Scientific Journal of Koya University, vol. 3, no. 1, pp. 23-27, 2015.

[12] G. S. Sidhu, P. S. Singh, and G. S. Mudahar, "Energy absorption build-up factor studies in biological samples," Radiation Protection Dosimetry, vol. 86, no. 3, pp. 207-216, 1999.

[13] G. S. Sidhu, P. S. Singh, and G. S. Mudahar, "A study of energy and effective atomic number dependence of the exposure build-up factors in biological samples," Journal of Radiological Protection, vol. 20, no. 1, pp. 53-68, 2000.

[14] K.-T. Chang, Computation for Bilinear Interpolation: Introduction to Geographic Information Systems, McGraw-Hill, New York, NY, USA, 7th edition, 2014.

[15] Wikipedia, 2017, Bilinear Interpolation. https://en.wikipedia .org/wiki/Bilinear_interpolation.

[16] InverstmentMine, 2017. Lead Prices and Lead Price Charts. http://www.infomine.com/investment/metal-prices/lead/.

[17] InverstmentMine, 2017. Iron Prices and News. http://www .infomine.com/investment/iron-ore/.

[18] G. S. Sidhu, P. S. Singh, and G. S. Mudahar, "Estimation of exposure buildup factor in iron using different method: A comparative study," Journal of Nuclear Energy Science \& Power Generation Technology, vol. 3, no. 2, 6 pages, 2014. 


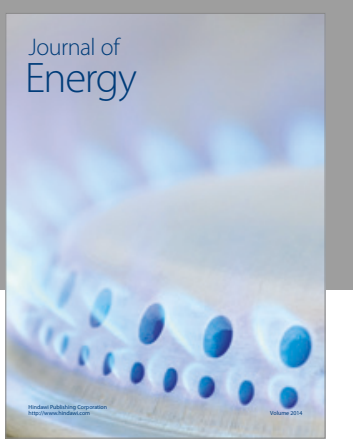

Journal of

Industrial Engineering
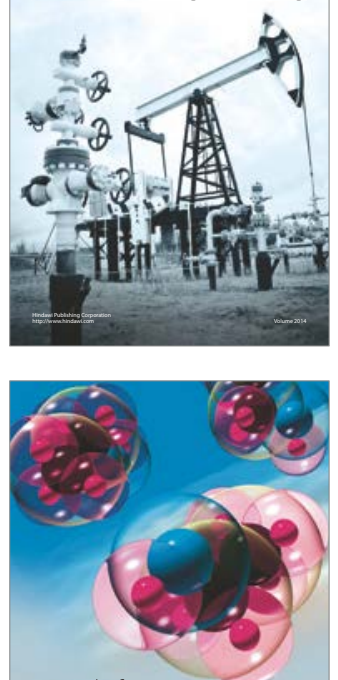

Fuels

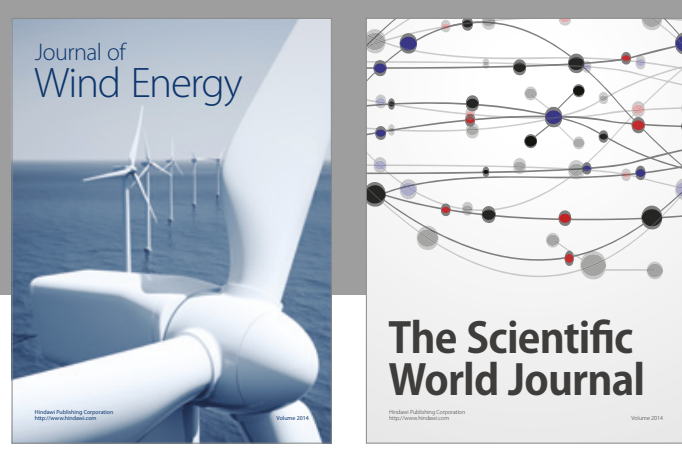

The Scientific World Journal
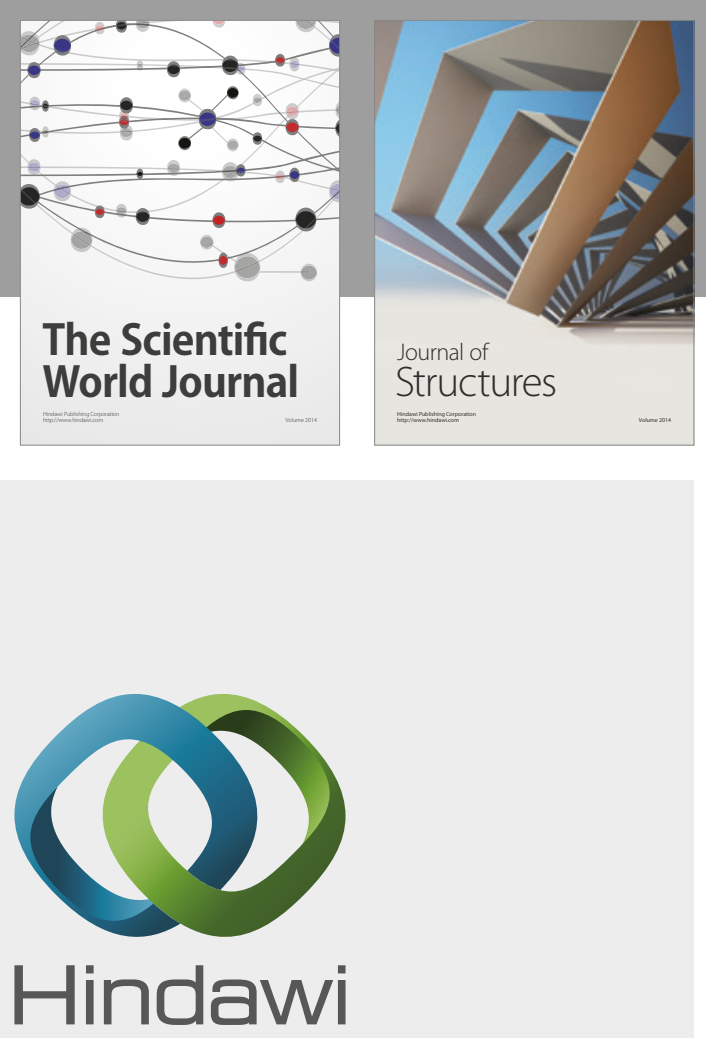

Submit your manuscripts at

https://www.hindawi.com


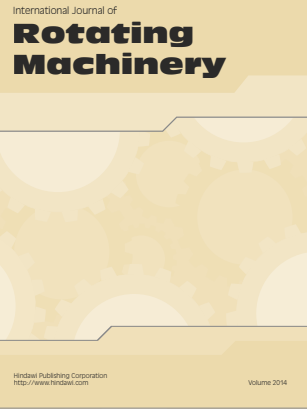

Journal of

Petroleum Engineering

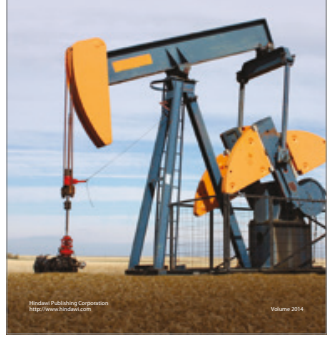

Journal of
Solar Energy
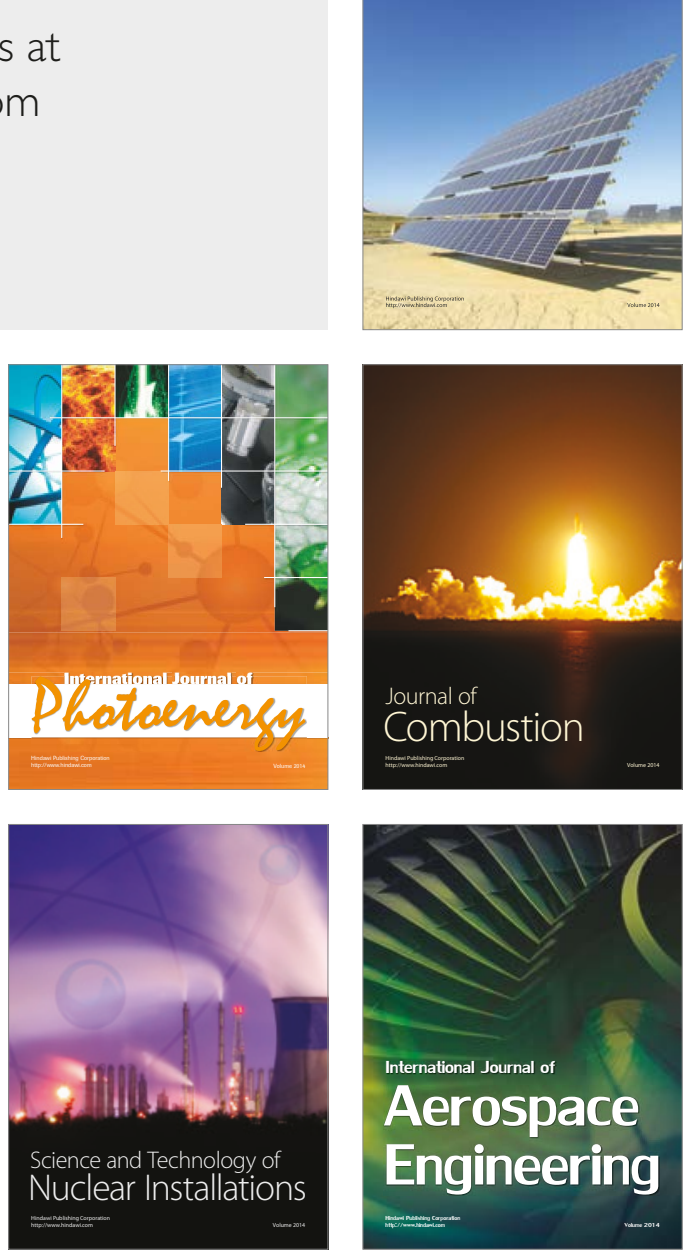